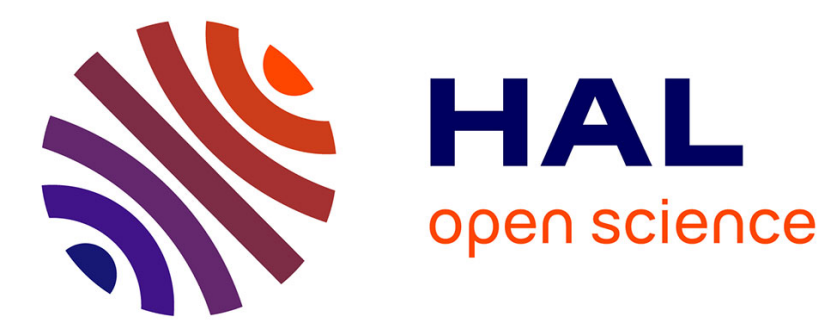

\title{
Cerebrovascular reactivity and dynamic autoregulation in ischaemic subcortical white matter disease
}

\author{
Jonathan Birns, Jozef Jarosz, Hugh S Markus, Lalit Kalra
}

\section{To cite this version:}

Jonathan Birns, Jozef Jarosz, Hugh S Markus, Lalit Kalra. Cerebrovascular reactivity and dynamic autoregulation in ischaemic subcortical white matter disease. Journal of Neurology, Neurosurgery and Psychiatry, 2009, 80 (10), pp.1093. 10.1136/jnnp.2009.174607 . hal-00552778

\section{HAL Id: hal-00552778 \\ https://hal.science/hal-00552778}

Submitted on 6 Jan 2011

HAL is a multi-disciplinary open access archive for the deposit and dissemination of scientific research documents, whether they are published or not. The documents may come from teaching and research institutions in France or abroad, or from public or private research centers.
L'archive ouverte pluridisciplinaire HAL, est destinée au dépôt et à la diffusion de documents scientifiques de niveau recherche, publiés ou non, émanant des établissements d'enseignement et de recherche français ou étrangers, des laboratoires publics ou privés. 


\section{Title:}

Cerebrovascular reactivity and dynamic autoregulation in ischaemic subcortical white matter disease

\section{Authors:}

Jonathan Birns ${ }^{1,2}$ PhD MRCP, Jozef Jarosz ${ }^{3}$ MRCP FRCR, Hugh S Markus ${ }^{4}$ DM FRCP, Lalit Kalra ${ }^{1}$ MD PhD

\section{Affiliations:}

${ }^{1}$ Department of Stroke Medicine, Academic Neurosciences Centre, PO41, Institute of Psychiatry, King's College London, Camberwell, London SE5 8AF United Kingdom

${ }^{2}$ Department of Ageing \& Health, St Thomas' Hospital, London SE1 7EH, United Kingdom

${ }^{3}$ Department of Neuroradiology, King's College Hospital, Denmark Hill, London SE5 9RS United Kingdom

${ }^{4}$ Centre for Clinical Neuroscience, St George's, University of London, Cranmer

Terrace, London SW17 ORE United Kingdom

\section{Address for correspondence:}

Jonathan Birns, Department of Ageing \& Health, $9^{\text {th }}$ Floor, North Wing, St Thomas' Hospital, London SE1 7EH, United Kingdom

Tel.: +44-2071882515 Fax.: +44-2079282339 e-mail: jonathan.birns@gstt.nhs.uk

\section{Key words:}

autoregulation, vasoreactivity, small vessel disease

\section{Word count:}

2928 words 


\section{Disclosure:}

The authors report no conflicts of interest.

The corresponding author has the right to grant on behalf of all authors and does grant on behalf of all authors, an exclusive licence (or non exclusive for government employees) on a worldwide basis to the BMJ Publishing Group Ltd and its Licensees to permit this article (if accepted) to be published in the Journal of Neurology, Neurosurgery \& Psychiatry editions and any other BMJPGL products to exploit all subsidiary rights, as set out in the licence (http://jnnp.bmijournals.com/ifora/livence/pdf). 


\begin{abstract}
Background:

It has been suggested that impaired cerebral autoregulation and vasodilatory capacity may play in role in the pathogenesis of the leukoaraiosis seen in small vessel disease. Adequate perfusion of the deep white matter of the brain depends on the relationships between blood pressure (BP), cerebral vasoreactivity and autoregulation.
\end{abstract}

Methods:

24-hour ambulatory BP measurement, quantitative volumetric MRI analysis of white matter lesion (WML) volume and transcranial Doppler ultrasound assessments of $\mathrm{CO}_{2}$ reactivity in response to hypercapnia and dynamic cerebral autoregulatory index (ARI) were undertaken in 64 patients with cerebral small vessel disease.

Results:

Subjects had mean 24-hour BP 133/76 mmHg (SD 13/9), median WML volume 7169 (IQR 20497) $\mathrm{mm}^{3}$, mean $\mathrm{CO}_{2}$ reactivity 83.6 (SD 37.4) \% and mean ARI 5.6 (SD 1.4) (range 0-9). In multivariate models, after adjusting for age, gender, vascular risk profile and WML volume, ARI correlated with 24-hour mean BP levels $\left(\mathrm{R}^{2}\right.$ : 0.127, t: 2.440, $\mathrm{p}=0.019)$ and $\mathrm{CO}_{2}$ reactivity correlated with duration of hypertension $\left(\mathrm{R}^{2}\right.$ : $0.085, \mathrm{t}:-2.244, \mathrm{p}=0.029)$. In individuals with hypertension for more than 10 years, ARI also correlated with nocturnal BP dipping ( $\mathrm{r}=0.806, \mathrm{p}=0.002)$. ARI and $\mathrm{CO}_{2}$ 
reactivity were unaffected by WML volumes and ARI and $\mathrm{CO}_{2}$ reactivity were unrelated.

Conclusion:

Cerebral autoregulation and $\mathrm{CO}_{2}$ reactivity are two distinct processes which are not related to WML volume but are related to BP levels and duration of hypertension respectively. Greater nocturnal dipping was associated with higher ARI values, suggesting preservation of autoregulation in patients with increased vulnerability to reduced cerebral perfusion. 


\section{Introduction}

With the current emphasis on lowering BP to slow down progression of cerebovascular disease, ${ }^{1}$ a better understanding of cerebral vasoreactivity and autoregulation in patients with small vessel disease becomes very important. Whilst studies initially suggested that cerebral vasoreactivity was impaired in patients with small vessel disease, ${ }^{2-4}$ investigations that have excluded individuals with carotid artery stenoses or acute ischaemic events, that may have acted as confounding variables, have provided conflicting results. ${ }^{5-9}$ Limited evidence also exists on the relationships between small vessel disease and cerebral autoregulation. Cerebral autoregulation has been shown to be impaired in individuals with extensive leukoaraiosis on brain imaging, ${ }^{10-12}$ but there is a lack of data on the integrity of cerebral autoregulation in patients with small vessel disease and no concomitant large vessel disease.

Recent studies have emphasised the importance of physiological variations in BP in the prediction of cerebral blood flow (CBF) and cerebrovascular disease, particularly with reference to nocturnal BP fall. ${ }^{13-14}$ The integrity of cerebral vasoreactivity and autoregulation is crucial to maintaining a constant $\mathrm{CBF}$ in the face of such BP fluctuations. Cerebral autoregulation can be static i.e. adjustments in response to prolonged $\mathrm{BP}$ changes or dynamic i.e. ability to maintain $\mathrm{CBF}$ in the face of $\mathrm{BP}$ changes occurring over a matter of seconds. Dynamic cerebral autoregulation is more vulnerable to impairment because of the complex neural, metabolic, myogenic and possible endothelium-related mechanisms involved. ${ }^{6,15}$ The objective of this study was to assess vasoreactivity, vascular reserve and dynamic cerebral autoregulation in 
response to physiological variations in BP in patients with early evidence of cerebral small vessel disease using ambulatory 24-hour BP measurement, quantitative volumetric MRI analysis of cerebral small vessel disease and transcranial Doppler ultrasound (TCD) assessments of $\mathrm{CO}_{2}$ reactivity and dynamic cerebral autoregulation.

\section{Methods}

\section{Subjects}

The study was undertaken in 64 subjects over the age of 50 years with evidence of small vessel (lacunar infarction, leukoaraiosis) but not large vessel cerebrovascular disease on MR neuroimaging. Subjects were recruited prospectively (January 2003 June 2005) from a hypertension clinic in a teaching hospital where all patients underwent MR brain imaging as an investigation of target organ damage. All patients were on antihypertensive treatment at the time of the study. Participants were included in the study if they fulfilled the following criteria: (1) treated BP in the normotensive range (because of the known associations between impaired cerebral autoregulation and high or low BP); (2) no clinical history of a cerebrovascular disturbance (such as stroke, TIA or syncope) in the previous 3 months which may affect the integrity of cerebral autoregulation; (3) no clinical history of intermittent claudication or other symptoms of peripheral vascular disease (precluding autoregulatory assessments using thigh cuff inflation/deflation); (4) no cerebral large artery stenosis (>50\%); (5) no intracranial pathology other than cerebral small vessel disease on brain imaging; (6) no contraindication to MRI such as prosthetic heart valves, pacemakers, cochlear implants or claustrophobia. 
A detailed history was taken and a physical examination was performed in all individuals. Data were collected on demography, anthropometry and education, vascular risk profile including hypertension, diabetes mellitus, hypercholesterolemia, cigarette smoking and alcohol consumption. Hypertension was further characterised by its duration since diagnosis and drug treatment. Duplex ultrasound studies were performed to rule out significant $(>50 \%)$ carotid artery stenosis or abnormal blood flows in the carotid, vertebral or intracranial large arteries. The study was approved by King's College Hospital Ethics Committee and all patients provided informed consent.

Assessment of 24-hour ambulatory BP and cerebral small vessel disease lesion load

Non-invasive 24-hour ambulatory BP measurements (Tracker NIBP2, Reynolds Medical Limited, UK) were obtained on weekdays, with measurements being taken every 30 minutes during the day and every 60 minutes at night. Ambulatory BP monitor recordings were deemed to be insufficient if less than $70 \%$ of readings were successful. ${ }^{16}$ Day-time episodes were defined from 08:00 - 22:59 and night-time episodes from 23:00 - 07:59. CardioNavigator software (Reynolds Medical Limited, UK) was used to evaluate 24-hour, daytime and night-time systolic, diastolic and mean BP levels and pulse pressures. Nocturnal dipping of BP was calculated as described previously, where nocturnal dip rate $=(($ mean day BP - mean night $\mathrm{BP}) /$ mean day BP). ${ }^{17}$ 
Using a 1.0 T Siemens Magnetom Expert MR Scanner, whole brain axial fluid attenuated inversion recovery (FLAIR) and turbo spin-echo axial T2-weighted images were acquired to allow detailed visualisation of white matter disease. Images were transferred to a Centricity PACS workstation and WML volumes were calculated using a manual tracing technique as described previously. ${ }^{18}$ Intra-rater variability of WML volume measurements was assessed on 2 separate occasions in 10 subjects and the intra-class correlation coefficient was 0.99 (95\% CI: 0.95-1.0).

\section{TCD assessments}

\section{Instrumentation}

Subjects were in a supine position with their heads slightly elevated. TCD was used to measure the changes in middle cerebral artery velocity (MCAV) in response to changes in $\mathrm{BP}$ and inspired $\mathrm{CO}_{2}$. MCAV was recorded bilaterally simultaneously via the transtemporal window using $2 \mathrm{MHz}$ transducers (DWL, Langerach). Continuous BP recording was made via a servo-controlled finger plethysmograph (Finapres 2300, Ohmeda), with the subject's hand maintained at the same level as the head. Finapres measurements were initially corroborated by standard measurements of BP with an automated arm cuff (Omega 1400 series, In Vivo Laboratories Inc). End-tidal $\mathrm{CO}_{2}$

was measured with an automated capnograph (Normacap 200, Datex Instrumentation).

Assessment of dynamic cerebral autoregulation 
In order to assess dynamic cerebral autoregulation, a sudden stepwise drop in BP was induced by rapid deflation of bilateral thigh cuffs that had been inflated suprasystolically for 3 minutes. Autoregulatory responses were analysed off-line using the time-averaged mean velocities of the maximum velocity outlines of the Doppler spectrum and mean BP. Dynamic autoregulation was assessed as previously described using the software program supplied by the TCD manufacturers which compares the rate of return of $\mathrm{BP}$ and MCAV to baseline following the drop in BP. ${ }^{15,19}$ Starting at the moment of cuff release and based on the actual BP curve of the 30 seconds that followed, a series of 10 hypothetical MCAV autoregulatory curves were calculated that model between a passive MCAV and BP relationship (an autoregulatory index (ARI) of 0) and rapid rates of rise in MCAV with increased ARI (maximum ARI: 9; normal range: 5-9) (Figure 1). Full details of the equations used have been published previously. ${ }^{15}$ Five cycles of inflation/deflation were performed per subject with a 3 minute rest interval between cycles. A mean ARI was calculated for each subject only from runs in which a sufficient magnitude of BP fall (>10 mm Hg) was attained. Endtidal $\mathrm{CO}_{2}$ was recorded during and between repeated assessments of ARI. .

\section{Assessment of $\mathrm{CO}_{2}$ reactivity}

$\mathrm{CO}_{2}$ was administered as $8 \% \mathrm{CO}_{2}$ in air from a Douglas bag reservoir through a mask with inspiratory and expiratory limbs protected by one-way valves. End-tidal $\mathrm{CO}_{2}$ was monitored by continuous sampling from the expiratory limb using the automated capnograph. $\mathrm{CO}_{2}$ was administered until MCAV recordings had plateaued. $\mathrm{CO}_{2}$ reactivity was calculated off-line as the percentage increase in MCAV during $8 \% \mathrm{CO}_{2}$ inspiration, compared with baseline MCAV while breathing room air. ${ }^{5,7}$ Assessments 
of $\mathrm{CO}_{2}$ reactivity and autoregulation were performed on the same day but autoregulation was always evaluated first to avoid lasting effects of $\mathrm{CO}_{2}$ on the cerebral circulation. All reactivity and autoregulation traces were analysed by an experienced researcher blinded to patient identity and traces of poor quality were excluded prior to data analysis.

\section{Reproducibility study}

Ten subjects consented to assessment of ARI and eight subjects consented to assessment of $\mathrm{CO}_{2}$ reactivity at the same time and in the same environment on two consecutive days in order to assess reproducibility. The subjects were representative of the patients studied. The repeatability coefficient, which is equal to twice the SD of the differences between the pairs of measurements, ${ }^{20}$ was 2.4 for ARI assessment and $35.4 \%$ for $\mathrm{CO}_{2}$ reactivity assessment.

\section{Statistical analysis}

Data were tested for normality using the Kolmogorov-Smirnov test. Categorical data were compared using Chi-squared tests. Pearson's correlation coefficient (r) was used to examine correlations between normally distributed variables and logarithmic transformation of non-parametric data. Linear regression models with stepwise deletion were undertaken to examine the independent predictors of $\mathrm{ARI}$ and $\mathrm{CO}_{2}$ reactivity after adjusting for covariation in baseline characteristics of age, gender, vascular risk factor profile including BP level and duration of hypertension, and 
WML load and for variables significant at $\mathrm{p}<0.1$ on univariate analyses. All evaluations used SPSS statistical analysis software (version 13).

\section{Results}

Patient characteristics including 24-hour BP and WML volume measurements are shown in Table 1 . Of the 64 patients, 45 were on diuretics, 25 were on calcium channel antagonists, 33 were on ACE-inhibitors, 15 were on angiotensin II receptor antagonists and 20 were on alpha-adrenoceptor antagonists. 8 individuals (13\%) had a history of diabetes mellitus (mean (SD) duration: 7.5 (7.8) years), of whom 3 were insulin-dependent and 5 were taking oral hypoglycaemic therapy. 25 patients had evidence of nocturnal BP dipping (nocturnal reduction of BP by $>10 \%$ of daytime $\mathrm{BP}),{ }^{19}$ with a mean (SD) BP dip of $15.7(5.4) \mathrm{mm} \mathrm{Hg}$.

The MCAV was insonated at a mean (SD) depth of 51.6 (5.4) $\mathrm{mm}$. Mean (SD) MCAV was $56.8(16.5) \mathrm{cm} / \mathrm{s}$. Measurement of ARI was possible in 45 of the 64 patients. 10 individuals were unable to tolerate thigh cuff inflation/deflation, a stepped BP reduction $>10 \mathrm{~mm} \mathrm{Hg}$ with thigh cuff deflation could not be induced in 1 individual and in another 8 individuals, undulations in the continuous BP and/or MCAV recording traces precluded evaluation of ARI. There was no significant change in resting $\mathrm{CO}_{2}$ during or between repeated assessments of dynamic cerebral autoregulation. Mean (SD) ARI was 5.6 (1.4). In univariate analyses, ARI correlated significantly with 24-hour systolic BP $(r=0.327, p=0.030)$ and 24-hour mean BP $(\mathrm{r}=0.350, \mathrm{p}=0.020)$ (Figure 2) but not with diastolic BP or WML volume. In those individuals with a history of hypertension for more than 10 years, ARI also correlated 
significantly with nocturnal BP dipping $(\mathrm{r}=0.806$, $\mathrm{p}=0.002)$ (Figure 3). Regression analyses showed 24-hour mean BP to be an independent determinant of ARI $\left(\mathrm{R}^{2}\right.$ : 0.127, coefficient 0.060 (95\% CI: 0.010 to 0.109$)$, t: $2.440, \mathrm{p}=0.019$ ).

$\mathrm{CO}_{2}$ reactivity was assessed in 57 patients. 3 individuals were unable to tolerate $\mathrm{CO}_{2}$ inhalation and in another 4 individuals, undulations in the continuous BP and/or MCAV recording traces precluded assessment of $\mathrm{CO}_{2}$ reactivity. $\mathrm{CO}_{2}$ reactivity was not affected by patients' BP levels or WML volume but correlated negatively with duration of hypertension $(\mathrm{r}=-0.292, \mathrm{p}=0.027)$ (Figure 4). Duration of hypertension remained an independent predictor of $\mathrm{CO}_{2}$ reactivity in regression analyses $\left(\mathrm{R}^{2}\right.$ : 0.085 , coefficient -0.974 (95\% CI: -1.845 to -0.104$)$, t: $-2.244, \mathrm{p}=0.029)$. No significant relationships existed between ARI and $\mathrm{CO}_{2}$ reactivity and results were not affected by the class of antihypertensive treatment.

\section{Discussion}

This study in hypertensive patients with WML on MRI as a manifestation of cerebral small vessel disease showed that autoregulatory capacity was determined by BP levels and correlated with nocturnal BP dipping in individuals with longstanding hypertension. $\mathrm{CO} 2$ reactivity was not affected by patients' BP levels but was dependent on duration of hypertension. Neither ARI nor $\mathrm{CO} 2$ reactivity were significant determinants of WML volume.

Whilst cerebral autoregulation has previously been suggested to be impaired in

patients with small vessel disease, ${ }^{10-12}$ the mean \pm SD ARI in this study population 
was 5.6 \pm 1.4 (normal range: 5-9) ${ }^{15}$ suggesting that ARI is preserved in patients with early cerebral small vessel disease. This study differed from previous investigations in terms of excluding patients with large-vessel cerebrovascular disease and/or recent stroke that may have acted as confounding variables. ${ }^{6,21}$ Whilst ARI was unrelated to small vessel disease lesion load, ARI was associated with BP levels consistent with studies in normal volunteers. ${ }^{22-23}$ ARI increased with elevated 24-hour mean BP levels and also with nocturnal BP dipping in individuals with longstanding hypertension. The former relationship may be explained by ARI improving by increased vascular tone; acute elevation of BP with agents such as noradrenaline is associated with increased ARI. ${ }^{23}$ The latter relationship suggests that ARI is preserved even in longstanding hypertensives with cerebral small vessel disease. Recent studies have suggested that the threshold of BP needed to maintain CBF may shift to a higher level in elderly hypertensive individuals with small vessel disease and that physiological episodes of low BP may provoke ischaemic injury. ${ }^{24}$ Preservation of autoregulatory function in small vessel disease patients at greatest risk of reduced CBF may be a protective response analogous to the increase in oxygen extraction fraction seen in such patients. ${ }^{25}$

The linear relationship demonstrated between impaired $\mathrm{CO}_{2}$ reactivity and duration of hypertension has been suggested previously in animal studies. ${ }^{26}$ It has been proposed that an increased duration of exposure to systemic hypertension accelerates arteriosclerotic changes in the cerebral vasculature predisposing to increasing vessel wall rigidity and impaired cerebrovascular vasodilatory capacity. $\mathrm{CO}_{2}$ reactivity was unrelated to WML volume and this is consistent with previous studies that similarly excluded patients with concomitant large vessel disease or recent stroke. ${ }^{8-9}$ 
The findings of this study support the view that impaired cerebral autoregulation and limited vasodilatatory capacity are not pathogenetic hallmarks of leukoaraiosis. ${ }^{27}$ In addition, they support the concept that the cerebrovascular responsiveness to $\mathrm{CO}_{2}$ operates independently from cerebral autoregulation. In hypertensive subjects, cerebral autoregulation appears to be determined by the level of BP and is preserved in long-standing hypertensives, whereas responsiveness to $\mathrm{CO}_{2}$ is influenced by the duration of hypertension. Literature supports the concept of the two processes being distinct, having separate effector mechanisms, and interacting in a complex way. ${ }^{21,28,29}$ Although the physiology responsible for controlling CBF autoregulation and vasoreactivity is not fully understood, ${ }^{27}$ dynamic cerebral autoregulation has been suggested to be a more sensitive measure of haemodynamic impairment than $\mathrm{CO}_{2}$ reactivity. $^{21}$

In contrast to studies undertaken in untreated hypertensives or in patients whose antihypertensive treatment was discontinued, this study allowed patients to remain on pre-existing antihypertensive medications. This ensured the study population to be representative of the "norm", facilitating generalisability to the general population and it prevented participants having poorly controlled hypertension (clinic BP> 160/100 mmHg) that could act as a confounding influence. However, antihypertensive medications taken by patients may have exerted effects on the cerebral vasculature ${ }^{30}$ and the duration of undetected hypertension and effectiveness of previous BP control remain unquantifiable variables. 
The findings of this study are limited by the relatively small sample size, its crosssectional nature and the lack of a control group for comparison. This makes it possible that more subtle disturbances in haemodynamics or non-linear relations with small effect size in subjects with WML may have been missed. In addition, causal inferences should be made with caution, particularly with reference to the relationships between nocturnal BP falls and autoregulation, where both may be interlinked via other factors. Indeed, controversy exists in the literature with regard to prolonged and/or marked nocturnal dipping being physiological or abnormal, beneficial or harmful, and representing the cause or effect of end-organ damage. ${ }^{14,17,31}$

The high temporal resolution of TCD has made it the recognised method for estimating changes in $\mathrm{CBF}$ velocity in studies of cerebral autoregulation and vasoreactivity. ${ }^{4,32,33}$ Middle cerebral artery (MCA) blood flow velocity rather than blood flow has been used to determine cerebral haemodynamics. This is based on observations that changes in MCAV induced by BP drops during surgery correlate very closely with changes in internal carotid artery flow ${ }^{19}$ and that there is little change in MCA diameter during $\mathrm{CO}_{2}$ inhalation, ${ }^{34}$ suggesting that any change in MCAV measured by TCD is directly proportional to the change in flow. As TCD assessments measure the entire MCA territory and more blood flow goes to the grey matter than to the white matter, it is likely that TCD assessments reflect cortical more than the subcortical blood flow change. ${ }^{35}$ Although this is a potential limitation, it is likely that the pathology of small vessel disease is diffuse and TCD measurements provide a simple, non-invasive method for assessing cerebral autoregulation and vasoreactivity in these patients. 
The Finapres continuous BP recording used provided a reliable assessment of rapid changes in BP, but its accuracy for absolute measurement is affected by baseline shifts and unpredictable offsets. ${ }^{21}$ For the purposes of the autoregulation model, absolute measures of BP were not required but a lack of such values during assessment of $\mathrm{CO}_{2}$ reactivity did not demonstrate if $\mathrm{CO}_{2}$ inhalation produced a significant increase in BP that may have affected cerebrovascular reactivity. ${ }^{36} \mathrm{CO}_{2}$ inhalation was not tolerated by all patients and the thigh cuff technique was associated with pain on cuff inflation/deflation and difficulties in inducing significant BP drops with cuff deflation. The thigh cuff technique also could not be undertaken in subjects with peripheral vascular disease and it has been suggested that the technique may produce sympathetic activation. ${ }^{37}$ Although the thigh cuff method has been the most common approach for assessment of dynamic cerebral autoregulation, a number of other dynamic pressor or depressor stimuli exist but all have methodological limitations. ${ }^{33}$ Computerised coherent averaging of the CBF velocity response to spontaneous BP transients has also been developed, allowing calculation of ARI from spontaneous BP oscillations, but this was not available. ${ }^{38}$

In conclusion, this study demonstrated that cerebral autoregulation and $\mathrm{CO}_{2}$ reactivity appear to be two distinct processes that are not related to WML volume but are related to BP levels and duration of hypertension respectively. Greater nocturnal dipping was associated with higher ARI values in long-standing hypertensives with cerebral small vessel disease, suggesting preservation of autoregulation in patients with increased vulnerability to reduced cerebral perfusion. These findings suggest a complex interaction between BP, cerebral haemodynamics and chronic ischaemic injury to the 
brain that merits further investigation in the context of the increasing importance of cerebral small vessel disease and dementia in recent years. ${ }^{39}$ 


\section{References}

1. PROGRESS Collaborative Group. Randomised trial of a perindopril-based blood pressure-lowering regimen among 6105 individuals with previous stroke or transient ischaemic attack. Lancet. 2001; 358: 1033-41

2. Isaka Y, Okamoto M, Ashia K, Imaizumi M. Decreased cerebrovascular dilatory capacity in subjects with asymptomatic periventricular hyperintensities. Stroke. 1994; 25: $375-81$

3. Kuwabara Y, Ichiya Y, Sasaki M, Yoshida T, Fukumara T, Masuda K, Ibayashi S, Fujishima M. Cerebral blood flow and vascular response to hypercapnia in hypertensive patients with leukoaraiosis. Ann Nucl Med. 1996; 10: 293-8

4. Bakker SL, de Leeuw FE, de Groot, Hofman A, Koudstaal PJ, Breteler MM. Cerebral vasomotor reactivity and cerebral white matter lesions in the elderly. Neurology. 1999; 52: 578-83

5. Ringelstein EB, Sievers C, Ecker S, Schneider PA, Otis SM. Noninvasive assessment of $\mathrm{CO}_{2}$-induced cerebral vasomotor response in normal individuals and patients with internal carotid artery occlusions. Stroke. 1988; 19: 963-9

6. Dawson SL, Blake MJ, Panerai RB, Potter J. Dynamic but not static cerebral autoregulation is impaired in acute ischaemic stroke. Cerebrovasc Dis. 2000; 10: 12632

7. Markus H, Cullinane M. Severely impaired cerebrovascular reactivity predicts stroke and TIA risk in patients with carotid artery stenosis and occlusion. Brain. 2001; 124: 457-67 
8. Molina C, Sabin JA, Montaner J, Rovira A, Abilleira S, Codina A. Impaired cerebrovascular reactivity as a risk marker for first-ever lacunar infarction: A casecontrol study. Stroke. 1999; 30: 2296-301

9. Cupini LM, Diomedi M, Placidi F, Silvestrini M, Giacomini P. Cerebrovascular reactivity and subcortical infarctions. Arch Neurol. 2001; 58: 577-81

10. Marinoni M, Ginanneschi A, Ancona AL, Modesti PA, Piccininni, Inzitari D. Orthostatic transcranial Doppler variations in patients with leukoaraisois. Neurology; 1991: 41 Suppl 1: 123

11. Inzitari D, Ginanneschi A, Ancona AL, Piccinni M, Marinoni M. Evaluation of cerebral autoregulation in patients with leucoaraiosis. Ital J Neurol Sci. 1991; Suppl 5: 22

12. Matsushita K, Kuriyama Y, Nagatsuka K, Nakamura M, Sawada T, Omae T. Periventricular white matter lucency and cerebral blood flow autoregulation in hypertensive patients. Hypertension. 1994; 23: 565-8

13. Kario K, Shimada K, Pickering TG. Abnormal nocturnal blood pressure falls in elderly hypertension: clinical significance and determinants. J Cardiovasc Pharmacol. 2003; 41 Suppl 1: S61-6

14. Siennicki-Lantz A, Reinprecht F, Axelsson J, Elmstahl S. Cerebral perfusion in the elderly with nocturnal blood pressure fall. Eur J Neurol. 2007; 14: 715-20

15. Tiecks FP, Lam AP, Aaslid R, Newell DW. Comparison of static and dynamic autoregulatory mechanisms. Stroke. 1995; 26: 1014-9

16. van Boxtel MPJ, Henskens LHG, Kroon AA, Hofman PAM, Groneneschild EHBM, Jolles J, de Leeuw PW. Ambulatory blood pressure, asymptomatic cerebrovascular damage and cognitive function in essential hypertension. J Hum Hypertens. 2006; 20: 5-13 
17. Kario K, Matsuo T, Kobayashi H, Imiya M, Matsuo M, Shimada K. Nocturnal fall of blood pressure and silent cerebrovascular damage in elderly hypertensive patients. Hypertension. 1996; 27: 130-5

18. Birns J, Morris R, Jarosz J, Markus H, Kalra L. Ethnic differences in the cerebrovascular impact of hypertension. Cerebrovasc Dis. 2008; 25:408-16

19. Newell DW, Aaslid R, Lam A, Mayberg TS, Winn HR. Comparison of flow and velocity during dynamic autoregulation testing in humans. Stroke. 1994; 25: 793-7

20. Bland JM, Altman DG. Statistical methods for assessing agreement between two methods of clinical measurement. Lancet. 1986; 363: 307-10

21. White RP, Markus HS. Impaired dynamic cerebral autoregulation in carotid artery stenosis. Stroke. 1997; 28: 1340-4

22. Mahony PJ, Panerai RB, Deverson ST, Hayes PD, Evans DH. Assessment of the thigh cuff technique for measurement of dynamic cerebral autoregulation. Stroke. $2000 ; 31: 476-80$

23. White RP, Vallance P, Markus HS. Effect of inhibition of nitric oxide synthase on dynamic cerebral autoregulation in humans. Clin Sci (Lond). 2000; 99: 555-60

24. Kario K, Pickering TG. Blood pressure variability in elderly patients. Lancet. 2000; 355: $1645-6$

25. Meguro K, Hatazawa J, Yamaguchi T, Itoh M, Matsuzawa T, Ono S, Miyazawa H, Hishinuma T, Yanai K, Sekita Y, et al. Cerebral circulation and oxygen metabolism associated with subclinical periventricular hyperintensity as shown by magnetic resonance imaging. Ann Neurol. 1990; 28: 378-83

26. Yamori Y, Horie R. Developmental course of hypertension and regional cerebral blood flow in stroke-prone spontaneously hypertensive rats. Stroke. 1977; 8: 456-61 
27. Birns J, Kalra L. Pathogenesis of cerebral small vessel disease. Chapter 4. Brain Hypoxia Ischemia Research Progress. Nova Science Publishers. 2008

28. Immink RV, Secher NH, Van Lieshout JJ. Cerebral autoregulation and $\mathrm{CO}_{2}$ responsiveness of the brain. Am J Physiol Heart Circ Physiol. 2006; 291: H2018

29. Lundar T, Lindegaard KF, Froysaker T, Aaslid R, Grip A, Nornes H. Dissociation between cerebral autoregulation and carbon dioxide reactivity during nonpulsatile cardiopulmonary bypass. Ann Thorac Surg. 1985;40: 582-587

30. Walters M, Muir S, Shah I, Lees K. Effect of perindopril on cerebral vasomotor reactivity in patients with lacunar infarction. Stroke. 2004; 35: 1899-902

31. Sayk F, Becker C, Teckentrup C, Fehm HL, Struck J, Wellhoener JP, Dodt C.

To dip or not to dip: on the physiology of blood pressure decrease during nocturnal sleep in healthy humans. Hypertension. 2007; 49: 1070-6

32. Aaslid R, Lindegaard KF, Sorteberg W, Nornes H. Cerebral autorgeulation dynamics in humans. Stroke. 1989; 20: 45-52

33. Panerai RB. Assessment of cerebral pressure autoregulation in humans - a review of measurement methods. Physiol Meas. 1998; 19: 305-38

34. Huber P, Handa J. Effect of contrast material, hypercapnia, hyperventilation, hypertonic glucose and papaverine on the diameter of cerebral arteries. Invest Radiol. $1967 ; 2: 17-32$

35. Ramsay SC, Murphy K, Shea SA, Friston KJ, Lammertsma AA, Clark JC, Adams L, Guz A, Frackowiak RS. Changes in global cerebral blood flow in humans: effect on regional cerebral blood flow during a neural activation task. J Physiol. 1993; 471: 521-34

36. Panerai RB, Evans DH, Naylor AR. Influence of arterial blood pressure on cerebrovascular reactivity. Stroke. 199; 30: 1293-5 
37. Cencetti S, Fattorini L, Bacalli S, Bandinelli G, Cipriani M, Lagi A. Potential pitfalls in cerebral autoregulation testing. Cerebrovasc Dis. 1997; 7: 312

38. Panerai RB, Rennie JM, Kelsall AWR, Evans DH. Frequency-domain analysis of cerebral autoregulation from spontaneous fluctuations in arterial blood pressure. Med Biol Eng Comput. 1998; 36: 315-22

39. Moorhouse P, Rockwood K. Vascular cognitive impairment: current concepts and clinical developments. Lancet Neurol. 2008; 7: 246-55 
Table 1: Patient characteristics including 24-hour BP and WML volume measurements

\begin{tabular}{|c|c|}
\hline Mean (SD) age (years) & $63.7(9.0)$ \\
\hline$\%$ Male & 64 \\
\hline Mean (SD) duration of known hypertension (years) & $8.5(10.8)$ \\
\hline Mean (SD) HbA1c (\%) & $6.0(1.2)$ \\
\hline Mean (SD) serum cholesterol (mmol/l) & $4.9(0.9)$ \\
\hline$\%$ Current cigarette smokers & 16 \\
\hline \% Ex-cigarette smokers & 47 \\
\hline Mean (SD) alcohol use (units/week) & $8.6(16.3)$ \\
\hline Mean (SD) 24-hour SBP (mmHg) & $133.0(12.9)$ \\
\hline Mean (SD) 24-hour DBP (mm Hg) & $76.1(9.0)$ \\
\hline Mean (SD) 24-hour mean BP (mm Hg) & $93.6(8.9)$ \\
\hline Mean (SD) 24-hour pulse pressure (mm Hg) & $56.9(9.6)$ \\
\hline Mean (SD) day SBP $(\mathrm{mmHg})$ & $135.8(13.0)$ \\
\hline Mean (SD) day DBP (mm Hg) & $78.4(9.4)$ \\
\hline Mean (SD) day mean BP (mm Hg) & $96.0(9.4)$ \\
\hline Mean (SD) day pulse pressure $(\mathrm{mm} \mathrm{Hg})$ & $57.4(10.0)$ \\
\hline Mean (SD) night SBP (mmHg) & $127.4(15.5)$ \\
\hline Mean (SD) night DBP (mm Hg) & $71.4(10.4)$ \\
\hline Mean (SD) night mean BP (mm Hg) & $88.2(10.5)$ \\
\hline Mean (SD) night pulse pressure $(\mathrm{mm} \mathrm{Hg})$ & $56.0(10.0)$ \\
\hline Median (IQR) Total WML volume $\left(\mathrm{mm}^{3}\right)$ & $7169.4(20497.0)$ \\
\hline
\end{tabular}

$$
\mathrm{SBP}=\text { systolic } \mathrm{BP} ; \mathrm{DBP}=\text { diastolic } \mathrm{BP}
$$


Figure 1: Assessment of dynamic cerebral autoregulation

\section{$\mathrm{SBP} / \mathrm{mmHg}$}

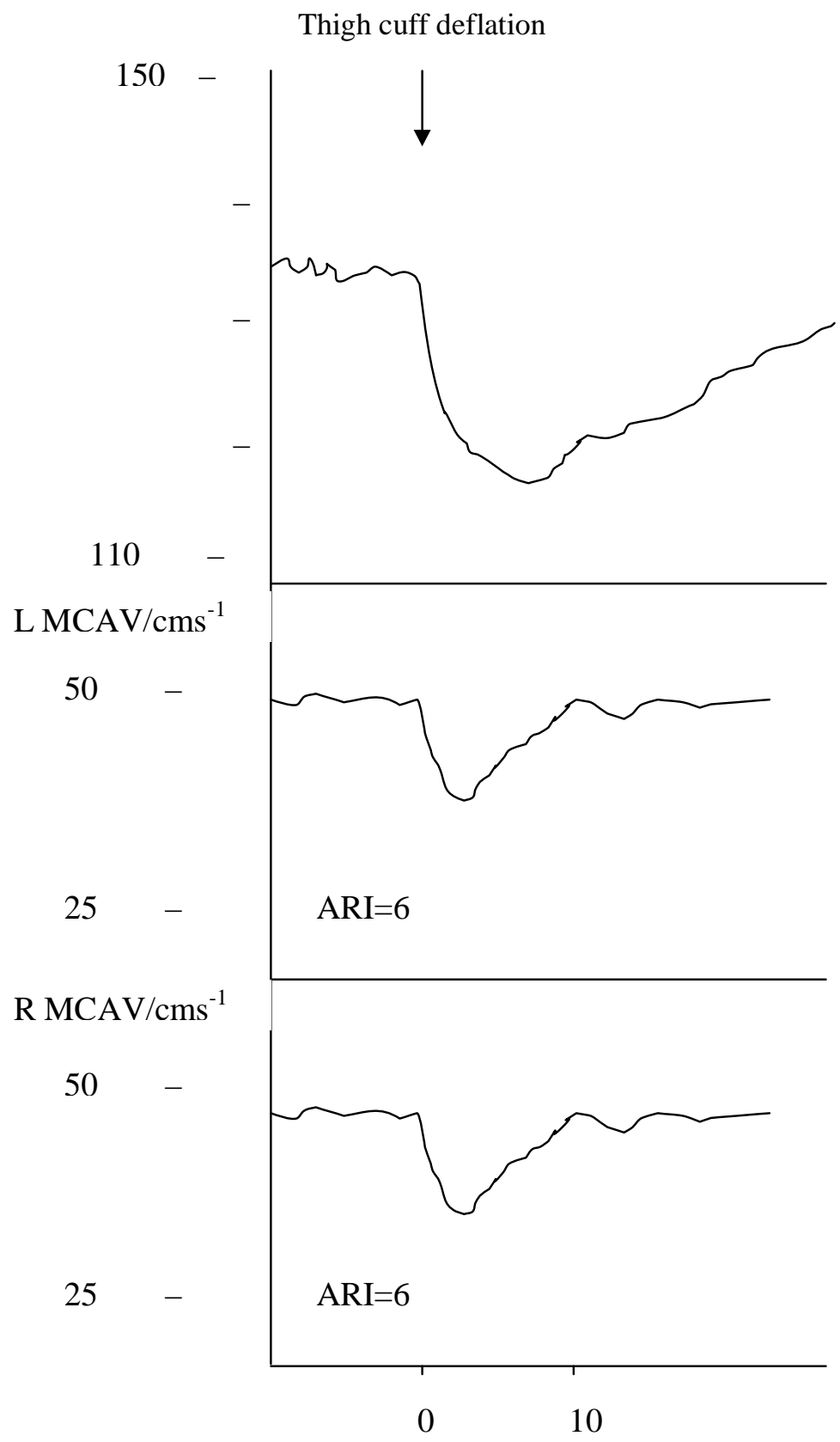

Normal dynamic cerebral autoregulation
Thigh cuff deflation

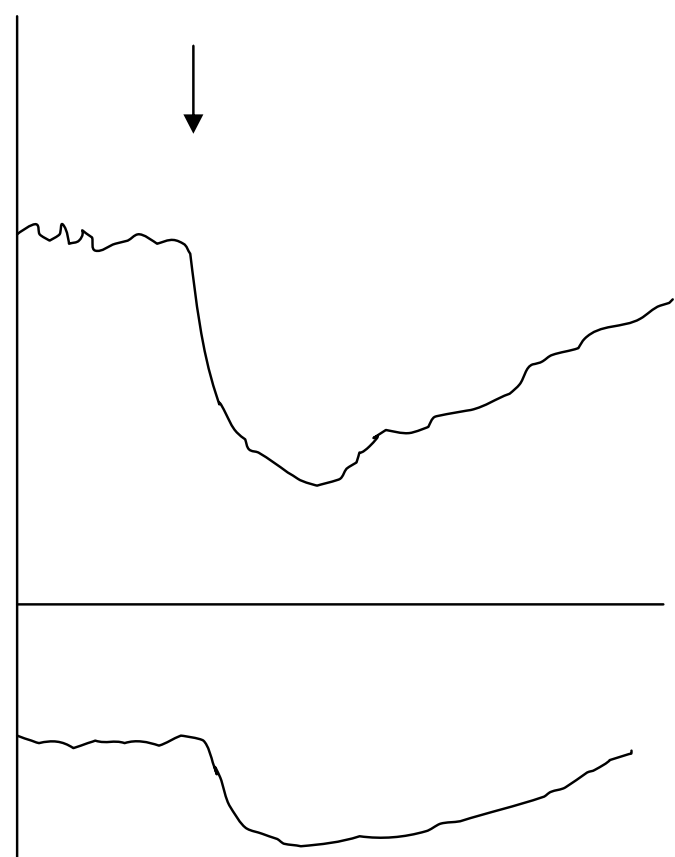

$\mathrm{ARI}=2$

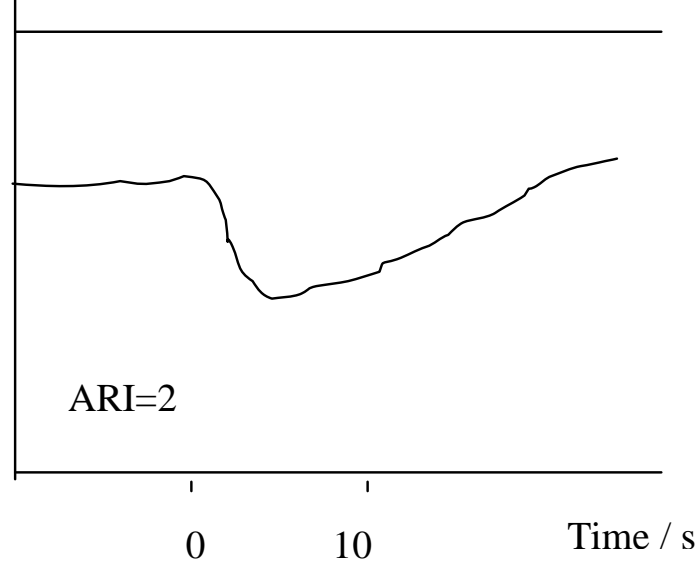

Impaired dynamic cerebral autoregulation

$\mathrm{SBP}=$ systolic blood pressure/mmHg; ARI = index of dynamic cerebral autoregulation; L MCAV and R MCAV = left and right middle cerebral artery velocities respectively/ $\mathrm{cms}^{-1}$

Adapted from Tiecks FP, Lam AM, Aaslid R, Newell DW. Comparison of static and dynamic cerebral autoregulation measurements. Stroke. 1995; 26: 1014-9 
Figure 2: Relationship between 24-hour mean BP and ARI

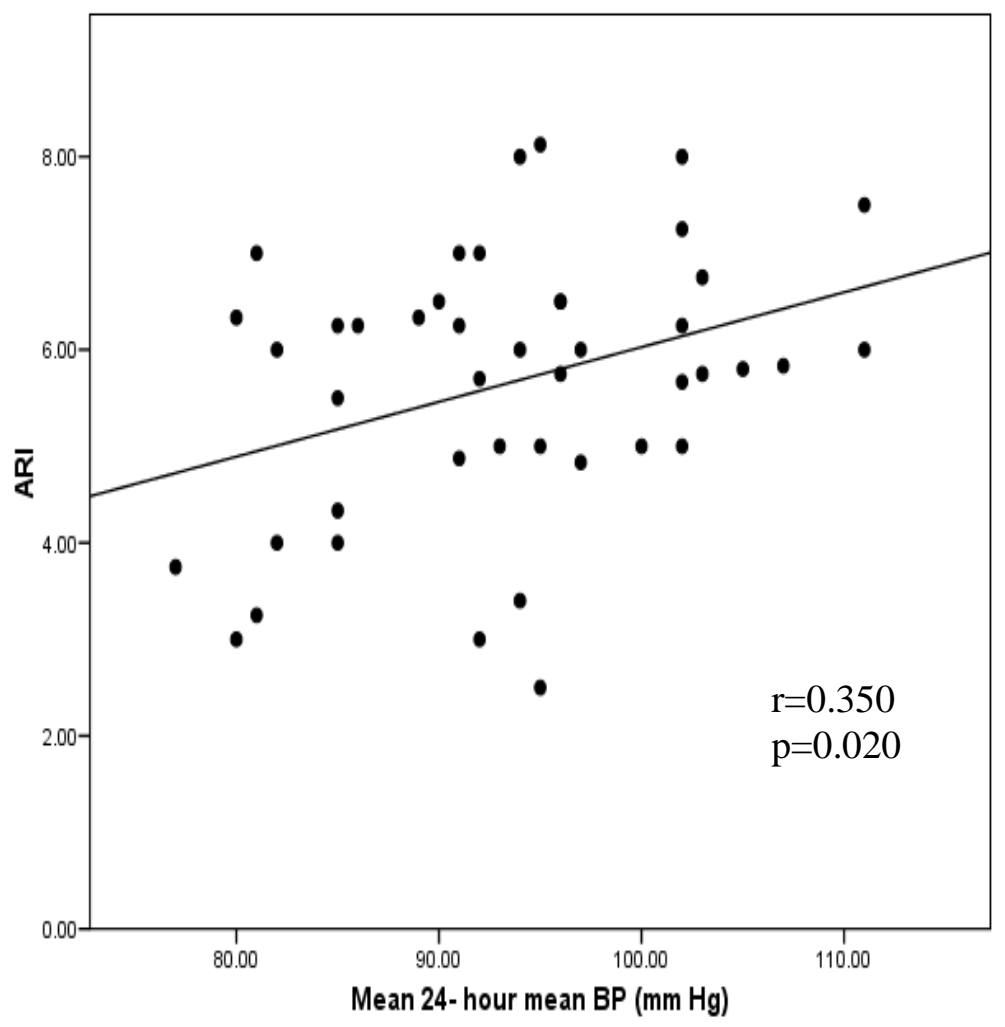


Figure 3: Relationship between nocturnal BP dipping and ARI

in individuals with a history of hypertension for more than 10 years

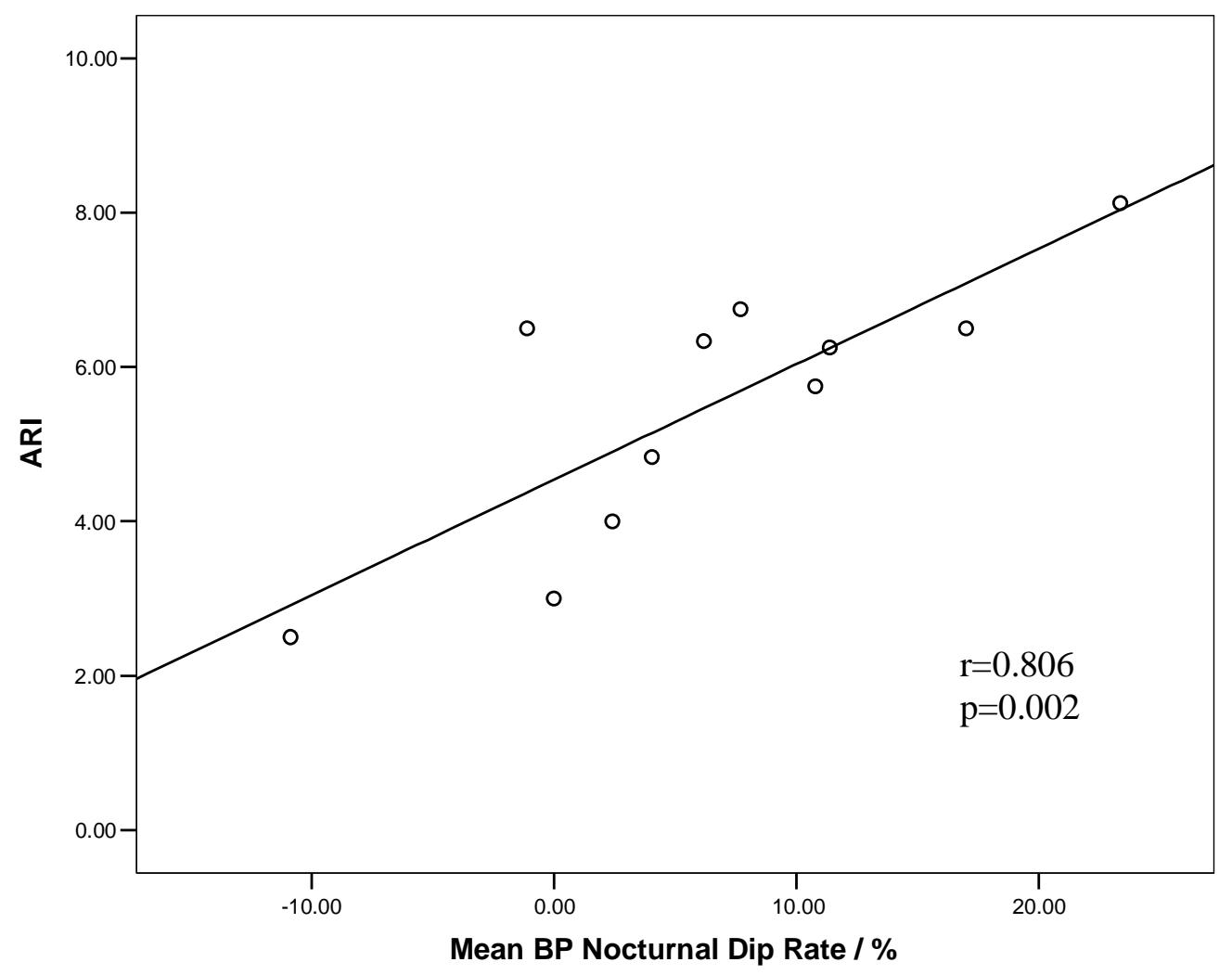


Figure 4: Relationship between duration of hypertension and $\mathrm{CO}_{2}$ reactivity

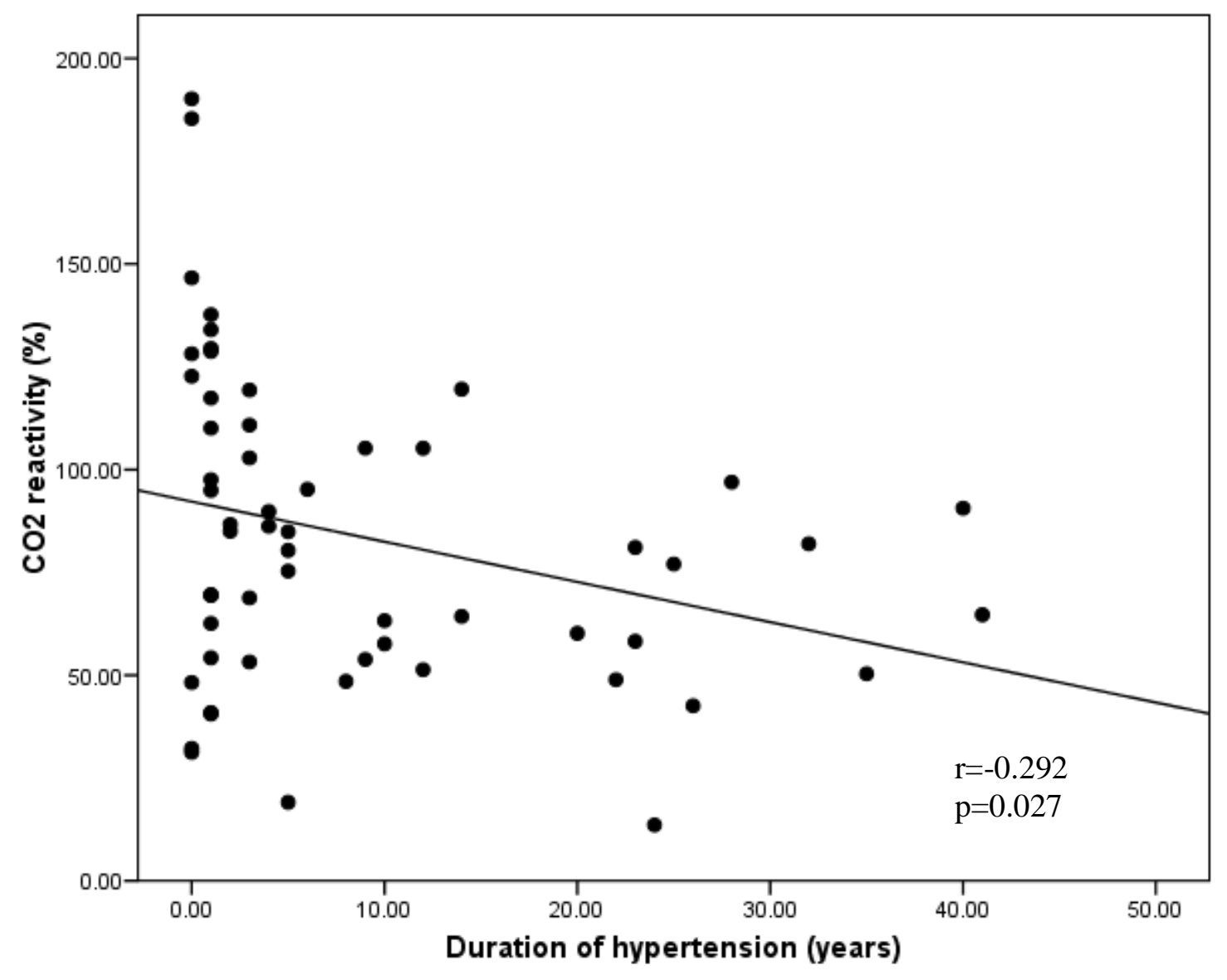

